Vol. I (2020), No. 1, pp. $62-76$

\title{
Digital strategy
}

\author{
Mladen TURUK ${ }^{\mathrm{a}}$
}

${ }^{a}$ Assistant Professor, University of Zagreb, Trg J.F. Kennedya 6, HR-10000 Zagreb, Croatia

\begin{abstract}
The digital strategy presents a framework for digital business transformation and an inevitable requirement for achieving success in a digital world. The pace of change and innovation in digital businesses is not slowing down and today almost no business can ignore its digital aspect but what drives digital transformation is a strategy, not technology. Therefore, the ability to digitally reimagine the business is determined by a clear digital strategy, and the leaders able to implement it in the organization. Inertia is not the solution to uncertainty. Having a clear vision, goals and objectives help organizations to reduce this ambiguity and adapt to an everchanging digital environment. Agile outperforms the traditional approach and new, innovative organizations replace incumbents that do not adapt fast enough in a process known as creative destruction.
\end{abstract}

Keywords: Digital Strategy, Digital Disruption, Business Transformation, E-Business, New Business Models

JEL Classification: L10, L21, L26

\section{Introduction}

The digital revolution has changed the lives of businesses and people worldwide and has forever changed the way we work and live. Using digital technologies in everyday lives has already become something we are familiar with. In the last two decades, we have seen advancements in technology that no one could have predicted, which have impacted many businesses and have forced them to redefine their business models. Nowadays IT is everywhere. It is embedded in many products and services and most interactions between consumers and suppliers are happening due to information technology. Technology advancements offer great potential for organizations to renovate their business to provide additional value to customers. IT not only shapes digital strategy but it also hugely affects overall business strategy as well and leads to completely new, technology-oriented business models. Businesses that do not adequately respond to the new turbulent business environment will be forced to leave the market in a process known as creative destruction.

Digital disruption, brought by fresh technological advances, caused social, economic, and organizational changes. Digital disruption can be defined as the rapidly 
unfolding processes through which digital innovation comes to fundamentally alter historically sustainable logics for value creation and capture by unbundling and recombining linkages among resources or generating new ones (Skog, Wimelius and Sandberg, 2018). It affected the way organizations function, compete, and cooperate with customers, partners, and other participants inside the ecosystem. The potential for business transformation is not limited to digital enterprises although they rely on diverse business models.

According the MIT Center for Digital Business and Capgemini Consulting (2011) three blocks that contribute to business model transformation are:

- "Digitally-modified business (through product/service augmentation, transforming a physical experience to a virtual/digital experience, or digital wrappers)

- New digital business (through digital products or via reshaping organizational boundaries)

- Digital globalization (through enterprise integration, shared digital services, etc.)".

Advances in digitization and developments in ICT are shaping the business environment, changing business practices, and creating prospects for new entrepreneurial activities (Ngoasong, 2015).

Present and arising digital technologies present both opportunities and risks for traditional organizations as well. New hi-tech trends, "such as mobile and social solutions, cloud computing, data analytics, digitization of manufacturing, including digital technologies for the design, prototyping, and testing of industrial products, as well as collaborative technologies, offer a new range of opportunities for business services in the knowledge economy" (European Commission, n.d.:1). Digital technologies offer tremendous growth opportunities but require entrepreneurs to fully unlock their economic potential as the basis of new businesses or an enabler of the transformation of already established firms (van Welsum, 2016). Technologies can and "should be used by existing and traditional businesses to digitally transform their activities in all areas. Those entrepreneurs who do not go along with the transformation process will lose their competitive positions on the market and may face consequences" (Turuk, 2018:185). Digital technologies are transforming the assembly of social relationships in the consumer and the enterprise space with social media networking (Susarla, Oh and Tan, 2012). More extensive use of cutting-edge digital technologies by SMEs has a positive impact on the economy as well as it can boost both growth and employment (The Boston Consulting Group, 2013).

Business models should be innovated and assimilated to the new market conditions. According to Osterwalder and Pigneur, (2010) there are four different epicenters of business model innovation: 
TURUK, M. / Digital strategy

- "Resource-driven

- Offer-driven

- Customer-driven

- Finance-driven".

The importance of digital technologies and new business models may best be illustrated in the well-known examples. Airbnb is the largest lodging provider owning no real estates, Alibaba became the highest valued retailer without inventory while Uber became the largest taxi operator owning no vehicles. It is clear how physical assets have been replaced by digital assets and intellectual capital. Nowadays, it becomes a necessity for organizations to understand digital strategies and their development in the digital world. This chapter aims to address what a digital strategy is and how is it developed. It will try to explain the purpose of a digital strategy and its position within an organization.

\section{Digital strategy: definitions and key themes}

Although recent studies have tried to explore the digital strategy, a clear, unique, and well-accepted definition of digital strategy does not appear to exist. Bharadwaj et al. (2013:472) define a digital strategy as "organizational strategy formulated and executed by leveraging digital resources to create differential value". Mithas, Tafti, and Mitchell (2013:513) claim digital strategy is "... the extent to which a firm engages in any category of IT activity... (and that it) emerges as a result of an interplay between a firm's digital strategic posture and industry environment". Woodard et al. define a digital strategy as "a pattern of deliberate competitive actions undertaken by a firm as it competes by offering digitally enabled products or services" (Woodard et al., 2013:538).

Organizations are faced with many key decisions regarding digital strategy but thoughtful consideration of the digital context is their starting position. According to Anderson MacGyver (2018) there are three key elements strategy development: the ability to plan and execute the activities for realizing those plans, and the ability to respond to both threats and opportunities in a timely manner. Questions such as how to act in a digitized world, how to respond to external digital opportunities and threats, or how to transform traditional values into digital values have become central questions from a strategic perspective.

Bharadwaj et al. (2013) identified four key themes to guide thinking on digital strategy:

- the scope of digital business strategy

- the scale of digital business strategy

- the speed of digital business strategy

- the sources of business value creation and capture in digital business strategy. 
Four key themes and questions referred to each theme are shown in Table 1.

Table 1. Key questions on digital strategy (Bharadwaj, 2013)

\section{Scope of Digital Business Strategy}

- What is the extent of fusion and integration between IT strategy and business strategy?

- How encompassing is a digital business strategy, and how effectively does digital business strategy transcend traditional functional and process silos?

- How well does digital business strategy exploit the digitization of products and services, and the information around them?

- How well does a digital business strategy exploit the extended business ecosystem?

\section{Scale of Digital Business Strategy}

- How rapidly and cost-effectively can the IT infrastructure scale up and down to enable a firm's digital business strategy to bolster a strategic dynamic capability?

- How well does digital business strategy leverage network effects and multisided platforms?

- How well does digital business strategy take advantage of data, information, and knowledge abundance?

- How effective is a digital business strategy in scaling volume through alliances and partnerships?

\section{Speed of Digital Business Strategy}

- How effective is a digital business strategy in accelerating new product launches?

- How effective is a digital business strategy in speeding up learning for improving strategic and operational decision making?

- How effectively does digital business strategy bolster the speed of dynamic supply chain orchestration?

- How quickly does digital business strategy enable the formation of new business networks that provide complementary capabilities?

- How effectively does the digital business strategy speed up the sense and respond cycle?

\section{Sources of Value Creation and Capture}

- How effective is a digital business strategy in leveraging value from information?

- How effective is a digital business strategy in leveraging value from multisided business models?

- How effective is a digital business strategy in capturing value through coordinated business models in networks?

- How effective is a digital business strategy in appropriating value through the control of the firm's digital architecture?

Scope deals with the degree of synthesis and integration between IT and business strategy, and how efficiently it transcends traditional functions and processes. This 
TURUK, M. / Digital strategy

theme also explores how well digital strategy exploits the digitization of products and services and how well digital strategy exploits business ecosystem.

Scale examines how fast and efficient can the IT infrastructure scale to allow a firm's digital strategy to boost a strategic capability, and how well digital strategy increases network effects. It also explores how well digital strategy takes advantage of information, data, and knowledge, and how efficient is a digital strategy in partnerships and alliances.

Speed examines how efficient is a digital strategy in speeding up launches of new product, and accelerating learning for increasing decision making. It also explores how efficiently does digital strategy boost the speed of supply chain composition, how fast it enables the creation of new networks that provide corresponding abilities, and how digital strategy accelerates the cycle.

Sources of value creation and capture examine how efficient is a digital strategy in generating value from information and business models as well as how efficient is a digital strategy in obtaining value through corresponding business models within networks and in seizing value through the control of the firm's digital assets. Drivers of the four key themes of digital business strategy are shown in Figure 1.

- Pervasive Connectivity

- Information Abundance

- Global Supply Chains

- Improved

Price/Performance of IT

- Growth of Cloud Computing

- Emergence of Big Data

- Limitations of Traditional Business Models

- Trans-functional Role for IT

- New Mandate for IT and the CIO

- Increased Familiarity with IT

Figure 1. Digital strategy drivers (Bharadwaj, 2013:473)

A person who is primarily in charge of digital strategy is a digital architect or digital strategist. The main purpose of having a digital strategy is to respond to digital disruption, allow organizations to survive in a digital world, and to find the best 
options to match consumer needs and therefore to achieve a competitive advantage. Various digital techniques such as data gathering, data analytics, artificial intelligence, machine learning can significantly improve the interaction between customer and supplier. Having a comprehensive digital strategy allows the company to maximize using digital assets and reaching its customers more effectively using different digital platforms.

\section{Digital strategy positions and key elements}

A digital strategy can be formed as a separate strategy or as a part of a main business strategy. If it is formed as a separate strategy it should be supported by conventional strategy as it is strongly intertwined within all vertical and horizontal parts of the organization. The position of a digital strategy is to transform existing business models using digital assets and upgrade their capabilities through technological advancements.

Advancements in technology have reduced barriers and provided an enlarged threat as additional products, primarily to traditional organizations. Digital technologies have become more affordable and widespread and have caused social, economic, and organizational implications. This chapter identifies and explains different strategic positions for being digital. Figure 2 represents four positions for a digital strategy based on different complexity levels of products and services and building relationships with customers.

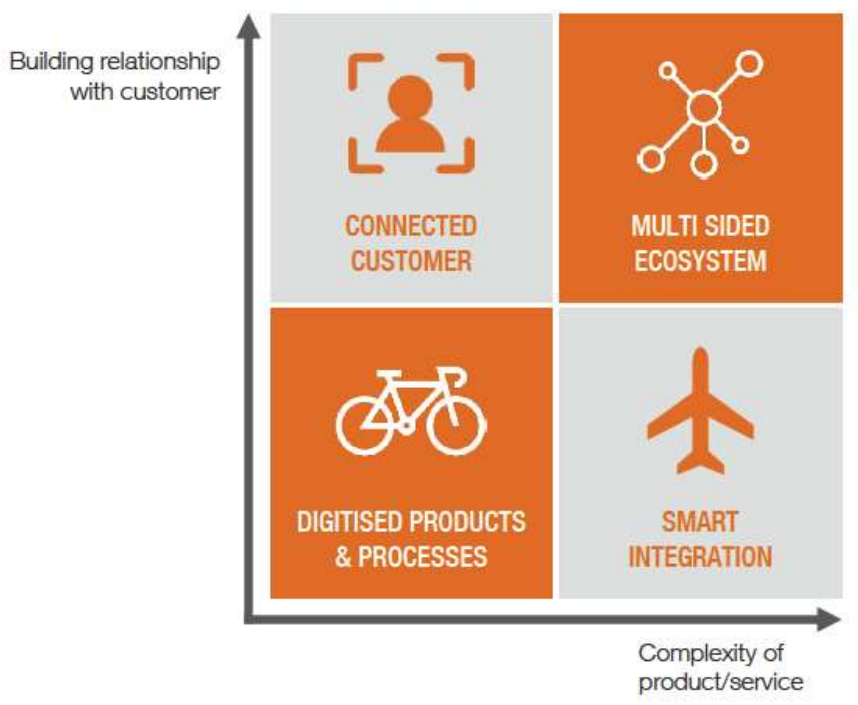

Figure 2. Four digital strategy positions (Anderson MacGyver, 2018:19) 
TURUK, M. / Digital strategy

Four digital strategy positions are:

- Digitized Products \& Processes

- Smart Integration

- Connected Customer

- Multi-sided Ecosystem.

Digitized Products \& Processes: Interaction with customers is primarily focused on transactions where products are relatively simple and easy to understand. Digital strategies in this situation create automation of production lines, end-to-end processing, automated processing, robotics, loT, data analysis for quality, and process engineering.

Smart Integration: Interaction with customers is primarily focused on the specifications of the product and its design. The interaction can be intense depending on the level of customization and complexity of the product. Products are complex, requiring a good understanding of customer needs. Digital investments in this situation are primarily focused on product design as well as the integration of many different technologies like mechanics, electronics, optics, aerodynamics, hydrodynamics, digitization, product and process engineering, and manufacturing.

Connected Customer: Interaction with customers is key, collecting valuable data and giving customer rewards in return. The aim is to offer a good customer experience by knowing customer needs. Connecting the customer means also offering multichannel experiences: online, mobile, social media, and shops.

Multi-sided Ecosystem: Strategy is based on deep interactive collaboration between customers, users, and business partners to offer an ecosystem (or platform) for doing transactions. The customer and their journeys on the ecosystem are key. The complexity of the platform is driven by the number of services that are offered through the platform and digital platforms are continuously enhancing the customer experience by offering more and more functionality through integrating more and more providers of services" [13: 20-21].

According to Business Queensland digital strategy is made up of nine key elements:

1) Online presence: How and where the community and other businesses see your business online. Your online presence includes:

- your business website, mobile website or a campaign mini-site

- social media profiles (Linkedln, Facebook, Twitter, YouTube, etc.)

- corporate advertising profiles

- links, information, reviews or articles appearing on other businesses' websites. 
2) Digital marketing: Promotion of the business using online resources and tools. (websites, micro-sites, mobile apps, and social media platforms). These may include online banner ads, search engine marketing, Facebook ads, Linkedln ads, blogs, guest blogs, newsletters, email marketing, mobile banner ads, and e-books.

3) Selling online: Using online selling allows customers to buy even when your shop doors are closed. Selling online typically helps reduce processing times internally, enabling to focus staff elsewhere in the business.

4) Customer interaction: Giving customers access to your business through whatever means they prefer - a mobile device, desktop computer, traditional phone call, or social media. It should require minimal effort from the customer to find the information, service, or product they are looking for.

To support your engagement with customers, you could use a customer relationship management (CRM) system to help you:

- capture and collate information about your clients

- track contacts, callbacks, and deals

- track the performance of your traditional and digital marketing strategies

- link your customer information with your accounting software.

5) Online security: The data and information stored on computers and servers are of utter importance and are often the most valuable, irreplaceable assets.

Online security may include:

- staff policies for accessing and storing company data, using digital technologies, and dealing with customer information

- cloud-based backup systems

- secure software and payment systems.

6) Supplier interaction: Have access to global and national markets to establish potential supplier relationships, as well as the capability to undertake supplier interactions more efficiently and effectively.

7) Mobile-based solutions: Integrating mobile-based solutions into your business through mobile commerce, mobile websites, and mobile applications to help customers complete specific tasks.

8) Efficiencies through technology: Using the right digital technology (hardware or software) for the right purpose can decrease business overhead. Efficiencies include the ability to process data faster, retrieve information more easily, and even downsize your business through the complete automation of suitable tasks. Decreases in human overheads can be achieved by moving business processes such as human resources and finance online. 
TURUK, M. / Digital strategy

9) Cloud computing: Storing and accessing data and programs over the internet instead of on the computer's hard drive. It can increase the capacity and add capabilities without investing in new infrastructure.

Figure 3 presents nine above key mentioned elements of digital business strategy.

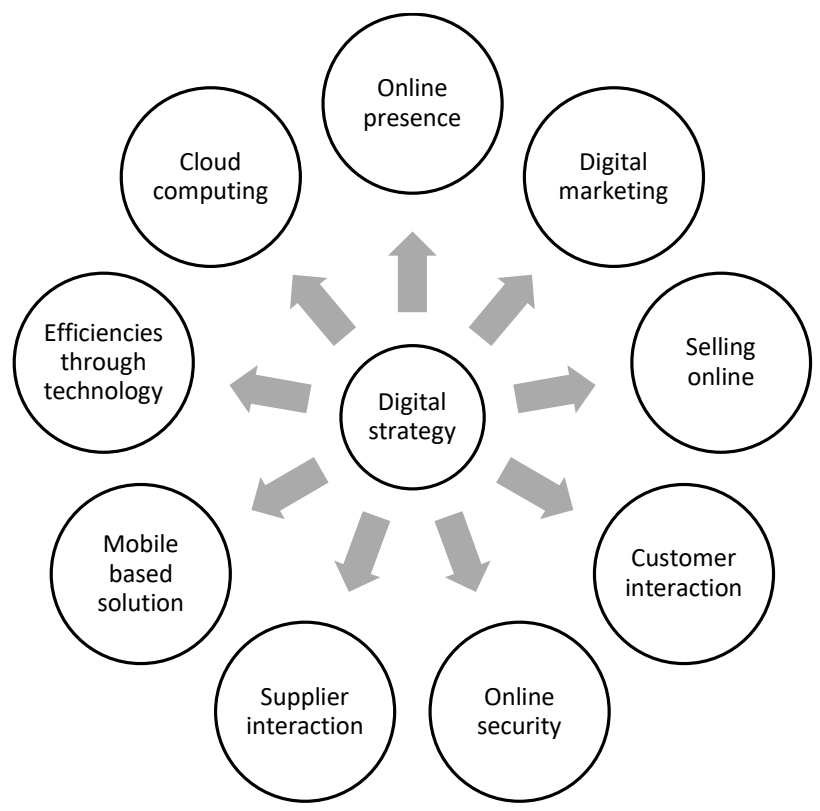

Figure 3. Nine elements of digital business strategy

Although business strategies are documents that are mostly adopted in the medium and long term, digital strategy is a document that, due to rapid changes in the technological environment, is often adopted in the short term, often for up to a year, or semi-annually or even quarterly.

\section{Digital strategy development}

The process of digital strategy development is a process that often includes extensive research and analysis. It is of utter importance to clearly define the aims for a digital strategy to provide solutions for their achievement. It is necessary to gain deep customer insights to evaluate potential strategic options. Prototyping and concepts may be encompassed in the process and the whole digital strategy development process is usually iterative and experimental. The process itself can 
combine a classic strategy development methods with methods such as design thinking.

Rum (2016) states there are 10 steps to building an effective digital strategy:

- Define Your "Why"

- Create Your Brand Story

- Define Your Goals

- Develop Audience Personas

- Create a Journey Map

- Identify Key Channels

- Develop a Content Strategy

- Draft a Content Calendar

- Plan Your Resources

- Simply Measure.

The digital strategy development process steps are shown in Figure 4.

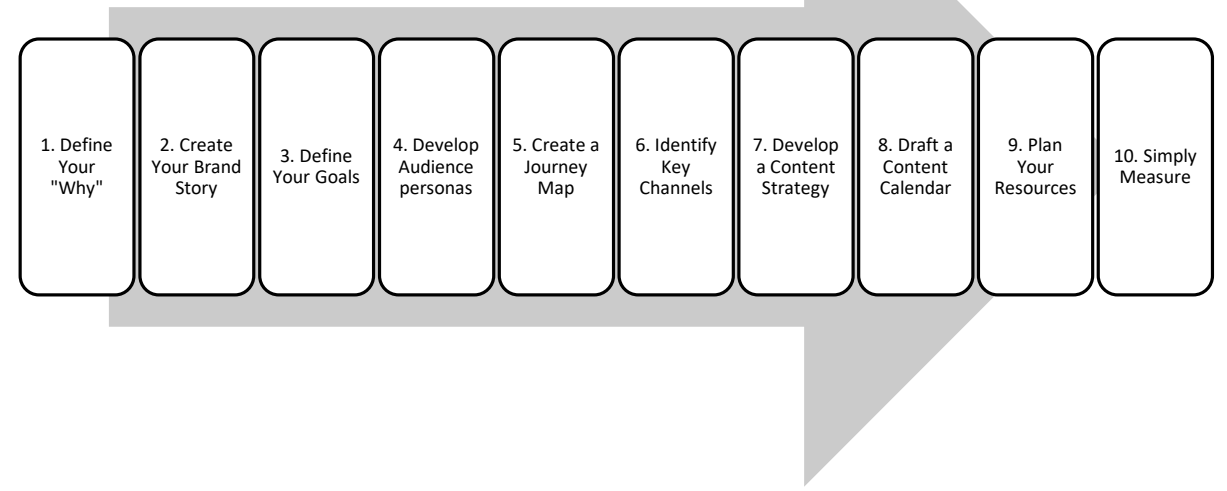

Figure 4. 10 steps to building an effective digital strategy (Rum, 2016)

Although the question why your company exists may sound simple the answer to the question may have to go deep. Once "why" is identified creating a digital strategy will seem much clearer. The next important question is "what's your brand story?". When identified why the company exists it is necessary to get your customers familiar with it. A brand needs to identify what your customers should expect from your organization. At least the top three goals should be clearly stated and used as further guidance. Goals should be achievable and formulated using a SMART methodology 
TURUK, M. / Digital strategy

(specific, measurable, attainable, realistic, and time-bound). It is necessary to identify the target audience, their background, values, age, career, etc., as those are customers being targeted. Once the target audience is clear, the next step is to create a journey map that will help to understand ways people are interacting with the organization. The more this is understood, the more detailed the journey map can be and hence digital strategy can be more potent. Nowadays, there are many different channels on how you can access target customers. It is not necessary to have all the channels but to opt for those most used by the target customers and put focus only on them. Once channels are identified, good content is what attracts the customers and stick them on the channels. Dynamics of the content, whether the content is created daily, weekly, or monthly is based depends upon the robustness of the campaign. Drafting a content calendar is useful as it can show the clear workflow of the campaign. Planning the resources, such as staff, time and money is critical for the campaign. The majority of the channels have their analytics which can be used to track whether the goals are being achieved and whether the strategy fulfills the expectations.

Alongside traditional approaches in the process of strategy development, design thinking is a relatively new approach for generating ideas. Design thinking is "a comprehensive customer-oriented innovation approach that aims to generate and develop creative business ideas or entire business models" (Mueller-Roterberg, 2018). It is a method for solving complex problems and generating innovative solutions based on a customer-centered approach. Kimbell emphasizes three design thinking conceptualizations: "(1) A cognitive style of individual designers used to solve illdefined problems by employing abductive thinking; (2) A broad theory of design used by the design discipline to address 'wicked problems'; and (3) An organizational resource used to innovate through demonstrating empathy and employing techniques such as visualization, prototyping, integrative thinking, and abductive thinking" (Kimbell, L., 2011:297).

Design thinking is closely related to empathy as the central element of the methodology is to put oneself in the position of the customer and to observe his behavior in detail. The Empathize mode is "the work you do to understand people, within the context of your design challenge. It is your effort to understand the way they do things and why, their physical and emotional needs, how they think about the world, and what is meaningful to them" (Plattner, H., n.d.). The purpose is "to foster empathy and deep understanding of the users in terms of their life, needs, aspirations, and challenges; appreciate others as human beings and understand and relate with their feelings; see their world through their eyes and make an emotional connection; communicate understanding with others and share their world; be in the shoes of your users, experience same and gain fresh insights and uncover their needs; and develop a passion to act and help and inspire us to find new solutions" (Chong Hwa et al., n.d.:17). 
Throughout the whole process customer and empathy should be in the main focus. Design thinking process consists of six process steps with iteration loops: Understanding, observing, defining problems, finding ideas, developing prototypes and testing (Plattner, Meinel and Weinberg, 2009). Figure 5 shows the steps of the design thinking process.

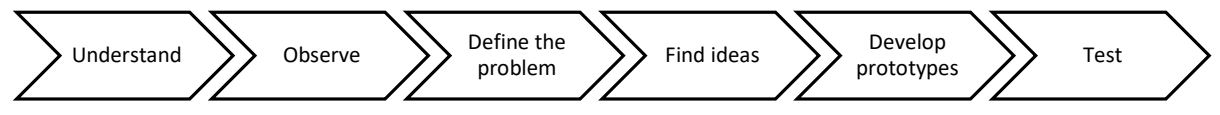

Figure 5. Design thinking process

In the first phase, it is crucial to understand the problem that needs to be solved. When understood, detailed on-site and off-site observations on the customer's problem are carried out. Usually, it includes interviews, surveys, and recordings. It aims to observe the customer's behavior as accurately as possible. After understanding and observation, the problem should be clearly defined. In the next phase brainstorming and other creativity, techniques take place to find the ideas and potential solutions to the problem. Ideas should be visualized and made tangible in the form of a prototype and in the final phase further developed and tested.

Design thinking represents is a methodology that places customers at the center of the innovation process can be applied across different disciplines and different industries. Design thinking should move beyond traditional boundaries to provide full results for the strategists. If used properly, design thinking can help any experts and professionals to solve problems in innovative ways.

\section{Conclusion}

The introductory part of the chapter provides a brief overview of using digital technologies and their importance in everyday lives. Digital disruption, brought by recent technological advances, caused social, economic, and organizational changes. It affected the way organizations operate, compete, and collaborate with customers, partners, and other stakeholders within the ecosystem. It also refers to the importance of developing a new business model and/or innovation. As there is no unique definition of digital strategy, the following part provides different digital strategy definitions and key themes, followed by digital strategy positions and its key elements. Furthermore, the process of digital strategy development and methods such as design thinking are explained in the following part.

There are many reasons for adopting a digital strategy. Digital strategies present organizations' response to digital disruption and help them survive in a world intertwined with digital technologies. The main aim of digital strategies is to optimize the use of digital technologies to achieve business objectives and gain a competitive 
TURUK, M. / Digital strategy

advantage. Markets are intensively changing and present business models are put to test by new, technology-oriented models. Keener use of information and technology becomes the key element of such models. Digital technologies are used to increase the performance and value of products and services. Becoming a digital organization means having technology at the centre all firms' activities and product line.

Digital strategies focus on customer experience and tend to redefine the present business models through digital assets and capabilities, especially in more traditional organizations. The process of digital transformation a company tends to go through often requires necessary support located in the main business strategy, but usually, it also means a cultural transformation as well. The process of digital strategy development includes research and analysis and the process may combine a classic approach with relatively new methods such as design thinking. Digital strategy development process includes defining the aims for the digital strategy as well as proposed solutions to realize them. The whole process may use prototyping, testing options, and concepts and is usually iterative and often experimental.

Future research on the topic may explore enablers of digital transformation within an organization as well as the digital strategy implementation process. This may be particularly interesting as the implementation of digital strategy affects many vertical levels within an organization so it would be interesting to further research how does digital strategy affect the conventional business strategy. It would also be interesting to explore in the vice versa direction or how a conventional business strategy may exploit digital assets and how this interrelationship may be continuously improved.

\section{References}

Anderson MacGyver, B.V. (2018) 'Digital Strategy: Building Your Company's Vision and Journey Towards Being Digital', Whitepaper 07

Bharadwaj, A., El Sawy, O.A., Pavlou, P.A., and Venkatraman, N. (2013) 'Digital Business Strategy: Toward a Next Generation of Insights', MIS Quarterly, Special Issue: Digital Business, 37(2), pp. 471-482

Business Queensland [Internet], Available at: https://www.business.qld.gov.au/running-business/it/digital-strategy/keycomponents (Accessed: 9 May 2020)

Chong Hwa L., Leow, J., Lau, J., Ho, A. and Hui Jong, C. (n.d.) Design Thinking: The Guidebook, Available at: https://www.rcsc.gov.bt/wp-content/uploads/2017/07/dtguide-book-master-copy.pdf (Accessed: 10 May 2020)

European Commission (n.d.) Strategic Policy Forum on Digital Entrepreneurship Fueling Digital Entrepreneurship in Europe, Available at: 
https://ec.europa.eu/docsroom/documents/5313/attachments/1/translations/en/ren ditions/native, (Accessed: 7 May 2020)

Kimbell, L. (2011) Rethinking Design Thinking: Part I. Design and Culture, 3(3), 285306, doi: 10.2752/175470811X13071166525216

MIT Center for Digital Business and Capgemini Consulting (2011) Digital Transformation: A Roadmap for Billion-Dollar Organizations, pp. 1-68

Mithas, S., Tafti, A., and Mitchell, W. (2013) 'How a Firm's Competitive Environment and Digital Strategic Posture Influence Digital Business Strategy', MIS Quarterly, 37(2), pp. 511-536

Mueller-Roterberg, C. (2018) Handbook of Design Thinking: Tips \& Tools for How to Design Thinking

Ngoasong, M. Z. (2015) Digital Entrepreneurship in Emerging Economies: The Role of ICTs and Local Context, 42nd AIB-UKI Conference Proceedings, 16-18 April 2015, Manchester Metropolitan University, UK, pp. 1-27

Osterwalder, A., and Pigneur, Y. (2010) Business Model Generation: A Handbook for Visionaries, Game Changers, and Challengers (1 ed.), Hoboken: Wiley

Plattner, H. (n.d.) An Introduction to Design Thinking Process Guide, Institute of Design at Stanford, Available at: https://dschoolold.stanford.edu/sandbox/groups/designresources/wiki/36873/attachments/74b3d/ ModeGuideBOOTCAMP2010L.pdf [Accessed: 10 May 2020]

Plattner, H., Meinel, C. and Weinberg, U. (2009) Design-Thinking, Munich: miWirtschaftsbuch

Rum, J. (2016) 10 Steps to Building an Effective Digital Strategy, Available from: https://www.socialmediatoday.com/marketing/10-steps-building-effective-digitalstrategy (Accessed: 6 May 2020]

Skog, D.A., Wimelius, H. and Sandberg, J. (2018) 'Digital Disruption', Bus Inf Syst Eng, 60, pp. 431-437, https://doi.org/10.1007/s12599-018-0550-4

Susarla, A., Oh, J-H., and Tan, Y. (2012) 'Social Networks and the Diffusion of UserGenerated Content: Evidence from YouTube', Information Systems Research, 23(1), pp. 123-141

The Boston Consulting Group (2013) Ahead of the Curve - Lessons on Technology and Growth from Small-Business Leaders, Available from: https://imagesrc.bcg.com/Images/Ahead_of the_Curve_Oct 2013 tcm9-94245.pdf (Accessed: 8 May 2020] 
TURUK, M. / Digital strategy

Turuk, M. (2018) 'The Importance of Digital Entrepreneurship in Economic Development', In: Proceedings of the $7^{\text {th }}$ International Scientific Symposium "Economy of Eastern Croatia - Vision and Growth"; 24-26 May 2018; Osijek, Croatia, pp. 178-186

van Welsum, D. (2016) Enabling Digital Entrepreneurs, World Development Report, Background Paper - Digital Dividends, pp. 1-12

Woodard, C. J., Ramasubbu, N., Tschang, F. T., and Sambamurthy, V. (2013) 'Design Capital and Design Moves: The Logic of Digital Business Strategy', MIS Quarterly, 37(2), pp. 537-564 